\title{
Electrophysiological effects of lorcainide, a new antiarrhythmic drug
}

\section{Observations in patients with and without pre-excitation}

\author{
FRITS W BÄR, JERÓNIMO FARRÉ, DAVID ROSS, EDGAR J VANAGT, \\ ANTON P GORGELS, HEIN J J WELLENS \\ From the Department of Cardiology, University of Limburg, Annadal Hospital, Maastricht, \\ The Netherlands
}

SUMMARY The electrophysiological effects of the intravenous administration of a new antiarrhythmic drug, lorcainide, were evaluated by programmed electrical stimulation of the heart in 23 patients with atrioventricular conduction disturbances (four patients), ventricular tachycardia (five patients), and accessory atrioventricular pathway (14 patients). Lorcainide did not affect the refractory period of the atrium, ventricle, atrioventricular node, or the $\mathrm{AH}$ interval. It lengthened the duration of the HV interval, the refractory period of the accessory pathway, and the width of the QRS complex. The drug terminated ventricular tachycardia in four of five patients. It is concluded that the drug may be of potential benefit in patients with ventricular tachycardia or accessory atrioventricular pathways (especially those with a short refractory period).

Lorcainide is contraindicated in patients with bundle-branch block and prolonged HV interval.

Lorcainide ( $R \quad 15889$ ) is a benzene-acetamide hydrochloride derivative. It is a new antiarrhythmic agent with local anaesthetic properties. The action of the drug can be partly explained by its selective reducing effect of sodium conductance. ${ }^{1}$

Our study was performed to investigate the specific electrophysiological effects of lorcainide in man.

\section{Subjects and methods}

Twenty-three patients were studied.

Four patients (two men and two women) had atrioventricular conduction disturbances. The ages of these patients ranged from 33 to 79, with a mean of 57 years. The conduction disturbance was located at the level of the atrioventricular node in one patient, the His bundle in one patient, and the bundle-branch system in two patients.

Five patients (two men and three women) had ventricular tachycardia. Their ages were 22 to 69 , mean 44 years. In two of these patients an old myocardial infarction was present. The other three were idiopathic. Twelve patients ( $10 \mathrm{male}$ and two female) suffered from the Wolff-Parkinson-White syndrome. Received for publication 12 May 1980
The age of these patients was 8 to 58 , mean 36 years. In nine the accessory pathway was located on the left side of the heart and in three on the right side. Ten of these patients had circus movement tachycardia.

A further two patients (one man of 43 years and one woman of 33 years) had a left sided concealed bypass tract.

Our methods of recording and stimulation during programmed electrical stimulation of the heart have been described previously. ${ }^{2}$

Informed consent was obtained, and four to five wires were passed through the femoral vein using the Seldinger technique. Two bipolar (or one quadripolar) wire(s) were positioned high on the lateral wall of the right atrium. One was used for stimulation, the other for recording an intra-atrial electrogram. A bipolar wire was placed in the region of the bundle of $\mathrm{His}$ to record the $\mathrm{His}$ bundle electrogram. A fourth (bipolar) wire was positioned in the apex of the right ventricle and used for ventricular stimulation.

In 13 patients a left atrial electrogram was recorded by way of a fifth wire (bi- or quadripolar) in the coronary sinus. This wire was also used for left atrial stimulation. In two patients a left atrial 
electrogram was also recorded from a wire in the main stem of the pulmonary artery.

In three patients with ventricular tachycardia a second bipolar wire was introduced in the ventricle: in two patients in the outflow tract of the right ventricle and in one patient in the left ventricle. Stimulation was performed at twice diastolic threshold both before and after lorcainide. All data obtained during the stimulation studies were recorded on a 16 channel Elema recorder. Leads I, II, III, V1, and V6, a right atrial lead, a left atrial lead, a His bundle recording, and sometimes a ventricular lead were recorded simultaneously.

Using the single test stimulus method during atrial stimulation the effective refractory period of the right atrium and the atrioventricular node, the functional refractory period of the atrioventricular node, the $A_{1} H_{1}$, the maximal $A_{2} H_{2}$, the $H_{1} V_{1}$, and the maximal $\mathrm{H}_{2} \mathrm{~V}_{2}$ interval were determined. The width of the His bundle electrogram and QRS complex were also measured.

During single test stimulation of the right ventricle the mode of VA conduction, the effective refractory period of the right ventricle, $Q R S$ width, and $V_{1} H_{1}$ and $V_{1} A_{1}$ intervals were determined. In patients with ventricular tachycardia, the rate and tachycardia zone were measured. In patients with an accessory pathway the effective refractory period of the extra connection in the anterograde and retrograde directions, tachycardia zone, rate, and $\mathrm{AH}, \mathrm{HV}$, and VA intervals during tachycardia were measured. The modes of initiation and termination of tachycardia were determined in all patients with tachycardia.

Previously described criteria ${ }^{3}$ were applied to determine the pathway used during ventriculoatrial conduction and the pathway used during re-entrant tachycardia. Measurements were repeated immediately after and continuously during the first 15 minutes, and then at 30,45 , and 60 minute intervals after the intravenous injection of lorcainide in a dose of $2 \mathrm{mg} / \mathrm{kg}$ bodyweight given over a five-minute period. Under results only the maximal changes in electrophysiological variables after lorcainide administration will be given. In patients where the exact value of the effective refractory period of the accessory pathway could not be determined because conduction over that structure occurred up to the effective refractory period of the atrium or ventricle, the increase after lorcainide can only be an approximation. Statistical analyses were performed using the paired $t$ test.

\section{Results}

ANTEROGRADE CONDUCTION OVER ATRIOVENTRICULAR NODE-HIS BUNDLE AXIs (Table 1)

During atrial pacing lorcainide had no significant effect on the effective refractory period of the right atrium, the effective refractory period of the atrioventricular node, the functional refractory period of the atrioventricular node, and the $\mathrm{A}_{1} \mathrm{H}_{1}$ and $\mathrm{A}_{2} \mathrm{H}_{2}$ intervals. The width of the His bundle electrogram increased by a mean of $2 \cdot 7 \pm 2.6 \mathrm{~ms}$. In addition, the $\mathrm{H}_{1} \mathrm{~V}_{1}$ interval increased by a mean of $22 \cdot 7 \pm 40 \cdot 0 \mathrm{~ms}$. The maximal $\mathrm{H}_{2} \mathrm{~V}_{2}$ interval did not change significantly, but the QRS width during regular atrial pacing lengthened by a mean of $20.4 \pm$ $14.4 \mathrm{~ms}$. The 12 patients with anterograde conduction over the accessory pathway are not included in Table 1.

After drug administration right bundle-branch block developed in two patients.

VA (HIS-ATRIOVENTRICULAR NODE) CONDUCTION

These observations were made in the nine patients

Table 1 Effect of lorcainide on electrophysiological data during atrial pacing*

\begin{tabular}{|c|c|c|c|c|c|c|}
\hline & \multirow[t]{2}{*}{ No. of patients } & \multicolumn{2}{|l|}{ Before } & \multicolumn{2}{|l|}{ After } & \multirow[t]{2}{*}{$P$} \\
\hline & & Range (ms) & Mean $\pm S D(m s)$ & Range (ms) & Mean $\pm S D$ (ms) & \\
\hline $\begin{array}{l}\text { ERPRA } \\
\text { ERPA vN } \\
\text { FRP }_{\text {A v }} \\
A_{1} H_{1} \\
A_{2} H_{2} \text { maximal } \\
H_{1} \\
H_{1} V_{1} \\
H_{2} V_{2} \text { maximal } \\
\text { QRS width }\end{array}$ & $\begin{array}{r}6 \\
6 \\
6 \\
11 \\
6 \\
11 \\
11 \\
6 \\
11\end{array}$ & $\begin{array}{r}190-280 \\
190-490 \\
300-520 \\
70-220 \\
150-330 \\
10-30 \\
35-130 \\
35-70 \\
80-170\end{array}$ & $\begin{array}{r}242 \pm 31 \\
287 \pm 104 \\
403 \pm 73 \\
105 \pm 44 \\
237 \pm 75 \\
20 \pm 6 \\
55 \pm 27 \\
52 \pm 14 \\
109 \pm 34\end{array}$ & $\begin{array}{c}200-270 \\
200-430 \\
310-440 \\
70-160 \\
140-410 \\
10-35 \\
40-270 \star \star \\
40-75 \\
85-210\end{array}$ & $\begin{array}{r}245 \pm 29 \\
272 \pm 82 \\
378 \pm 52 \\
103 \pm 24 \\
207 \pm 103 \\
22 \pm 7 \\
78 \pm 65 \\
71 \pm 32 \\
129 \pm 46\end{array}$ & $\begin{array}{l}\text { NS } \\
\text { NS } \\
\text { NS } \\
\text { NS } \\
\text { NS } \\
<0.01 \\
\text { NS } \\
\text { NS } \\
<0.001\end{array}$ \\
\hline
\end{tabular}

^Patients with Wolff-Parkinson-White syndrome are not included. Data on all parameters before and after drug administration were not available in all 11 patients.

$\star \star$ One patient developed complete HV block after lorcainide.

ERP, effective refractory period; RA, right atrium; $A V N$, atrioventricular node; FRP, functional refractory period. 
without accessory pathways. No significant effect of lorcainide was seen on the effective refractory period of the right ventricle. Before the drug the range was 230 to 290 , mean $256 \pm 25 \mathrm{~ms}$, and after lorcainide the range was 220 to 320 , mean $260 \pm 37$ ms (NS). The QRS width during regular ventricular pacing increased. Before the drug the range was 120 to 190 , mean $158 \pm 23 \mathrm{~ms}$, and after the drug it was 135 to $215 \mathrm{~ms}$, mean $178 \pm 25 \mathrm{~ms}$ $(p<0.001)$. VA delay developed after the drug in four out of the five patients showing retrograde conduction over the His-atrioventricular node pathway. Two of these four patients developed complete retrograde block below the His bundle.

\section{ATRIOVENTRICULAR CONDUCTION}

\section{DISTURBANCES}

In the patients with atrioventricular nodal and intraHisian block lorcainide had no effect on anterograde conduction.

This was in contrast to the two patients with conduction disturbances distal to the His bundle. Before the drug both patients had complete right bundle-branch block, left axis deviation, and an $\mathrm{HV}$ interval of $130 \mathrm{~ms}$.

After drug administration complete block distal to the His bundle developed in one patient and a $2: 1$ distal block in the other. The latter is shown in Fig. 1.

\section{VENTRICULAR TACHYCARDIA}

Before drug administration ventricular tachycardia could be initiated by a single test stimulus in four out of five patients. In the fifth patient spontaneous reinitiation of tachycardia always occurred im- mediately after pacing-induced termination of $\vec{\Rightarrow}$ tachycardia. The RR interval during tachycardia $\stackrel{0}{\rightarrow}$ before the drug varied from 280 to 470 , mean $405 \pm 87 \mathrm{~ms}$. After lorcainide administration the RR interval during ventricular tachycardia in- $\frac{5}{\sigma}$ creased in all patients, with a mean increase of $\stackrel{\varnothing}{\varrho}$ $71 \pm 30 \mathrm{~ms}$. The slowing in tachycardia rate was followed by spontaneous termination of tachycardia $\vec{\circ}$ in four out of five patients (Fig. 2). In only one patient were we not able to reinitiate tachycardia during programmed stimulation after lorcainide. There were no significant differences in mode of initiation and width of tachycardia zone in the of other three patients where ventricular tachycardia $\omega$ could be induced before lorcainide.

\section{EFFECT OF LORCAINIDE IN PATIENTS}

WITH ACCESSORY PATHWAY

Eleven patients with Wolff-Parkinson-White syndrome had sinus rhythm and both anterograde and retrograde conduction over the accessory pathway. One patient had atrial fibrillation. Two patients had a left sided concealed bypass and sinus rhythm.

\section{ANTEROGRADE CONDUCTION OVER}

ACCESSORY PATHWAY (Table 2)

In the 11 patients with sinus rhythm the effective refractory period of the accessory pathway was determined before and after drug administration. When possible we compared the effect on the effective refractory period of the accessory pathway from data obtained during stimulation of the atrial lead which was located closest to the atrial end of the accessory pathway.

If this was not possible (cases 14,17 , and 20) data

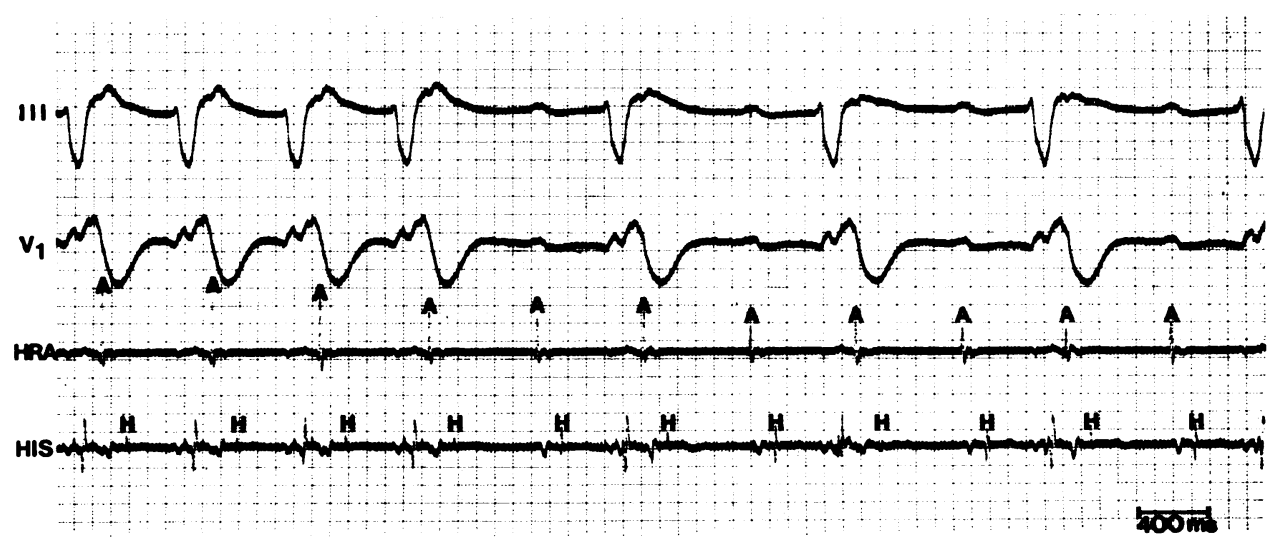

Fig. 1 Development of $2: 1$ block distal to His during lorcainide injection. Leads III, V1, a high right atrial lead $(H R A)$, and a His bundle lead were recorded simultaneously. 
from stimulation by way of the right atrial wire were used. Before the drug the effective refractory period of the accessory pathway in the anterograde direction varied from $<220$ to $410 \mathrm{~ms}$.

In eight out of the 11 patients drug administration resulted in a complete anterograde block of the accessory pathway (Fig. 3). In one patient the effective refractory period of the accessory pathway lengthened by $130 \mathrm{~ms}$. In the remaining two patients no effect was seen. Only one of the five patients with an effective refractory period of the accessory pathway $\leqslant 270 \mathrm{~ms}$ had conduction over the extra connection after the drug.

Atrial fibrillation was induced in six out of the 11

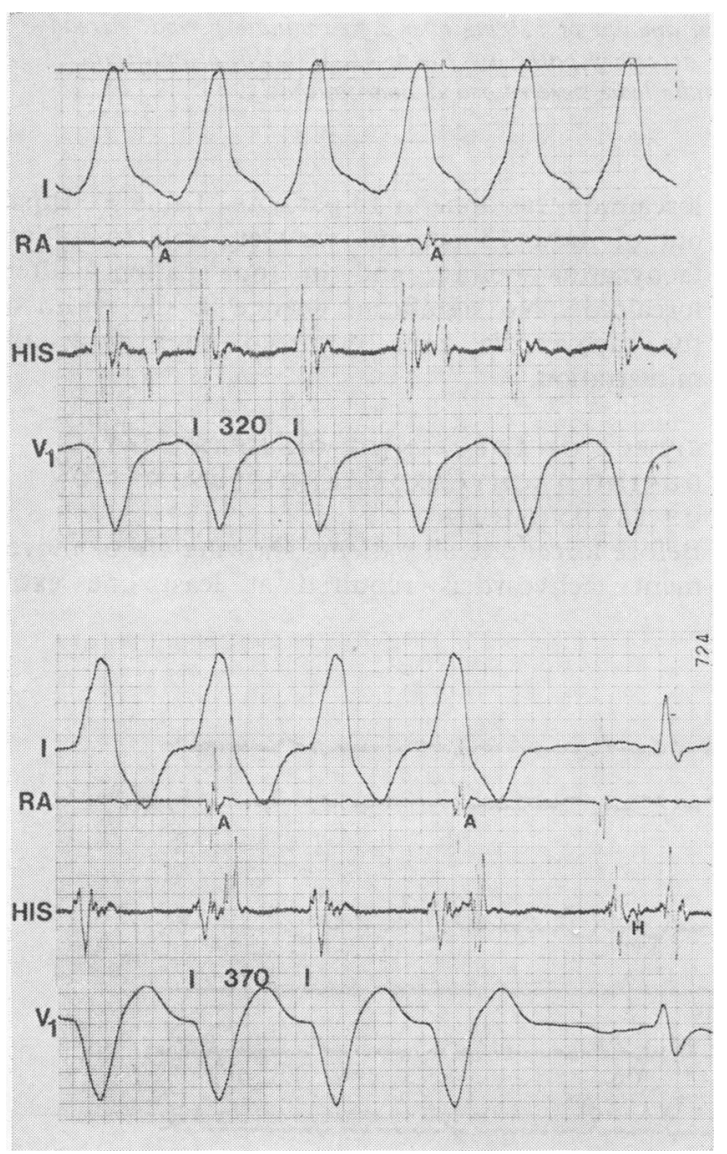

Fig. 2 Upper panel: ventricular tachycardia before drug administration. Lower panel: lorcainide administration results in a slowing in the rate of tachycardia followed by its termination. Leads I, V1, a high right atrial lead ( $R A$ ), and a His bundle lead were recorded simultaneously.
Table 2 Effect of lorcainide on anterograde ERP AP and tachycardia zone in 13 patients with WPW syndrome or concealed accessory pathway

\begin{tabular}{|c|c|c|c|c|c|c|}
\hline \multirow[b]{2}{*}{$\begin{array}{l}\text { Case } \\
\text { no. }\end{array}$} & \multirow[b]{2}{*}{$\begin{array}{l}\text { Site of } \\
\text { stimulation }\end{array}$} & \multirow[b]{2}{*}{$\begin{array}{l}\text { Basic cycle } \\
\text { length (ms) }\end{array}$} & \multicolumn{2}{|l|}{$E R P_{\mathrm{AP}}$} & \multicolumn{2}{|c|}{ Tachycardia zone } \\
\hline & & & $\begin{array}{l}\text { Before } \\
\text { (ms) }\end{array}$ & $\begin{array}{l}\text { After } \\
\text { (ms) }\end{array}$ & $\begin{array}{l}\text { Before } \\
\text { (ms) }\end{array}$ & $\begin{array}{l}\text { After } \\
(m s)\end{array}$ \\
\hline 1 & CS & 500 & 270 & $>500$ & 50 & 120 \\
\hline 2 & HRA & 500 & 410 & $>500$ & 60 & 20 \\
\hline 3 & HRA & 600 & 320 & $>600$ & 30 & 30 \\
\hline 4 & CS & 600 & 290 & 420 & 50 & 100 \\
\hline 5 & HRA & 470 & 260 & $>470$ & 60 & 60 \\
\hline 6 & HRA & 600 & 280 & 280 & 0 & 0 \\
\hline 7 & CS & 600 & 260 & 250 & 0 & 10 \\
\hline 8 & HRA & 600 & $<220$ & $>600$ & 0 & 80 \\
\hline 9 & HRA & 500 & 310 & $>500$ & 15 & 0 \\
\hline 10 & CS & 500 & 400 & $>500$ & 140 & NM \\
\hline 11 & $\mathrm{CS}$ & 500 & 230 & $>660$ & 10 & NM \\
\hline $12^{\star}$ & CS & 600 & - & - & 90 & NM \\
\hline $13^{\star}$ & HRA & 500 & 一 & - & 40 & 20 \\
\hline
\end{tabular}

ERP, effective refractory period; AP, accessory pathway; CS, coronary sinus; HRA, high right atrium; NM, not measured.

$\star$ Patients with a concealed left sided accessory pathway.

patients with sinus rhythm by pacing the atrium at high rates. In three out of these six patients atrial fibrillation could again be initiated after drug administration. In one patient lorcainide was given during atrial fibrillation; this patient had permanent atrial fibrillation. In the four patients showing atrial fibrillation before and after lorcainide the shortest RR interval between QRS complexes with pre-excitation was 220 to $250 \mathrm{~ms}$ before the drug. After lorcainide administration two patients had exclusive conduction over the atrioventricular nodal His connection. In the other two patients conduction over the accessory pathway continued. In one patient the shortest $R R$ interval during pre-excitation lengthened from 220 to $410 \mathrm{~ms}$; in the other patient no difference was observed.

\section{RETROGRADE CONDUCTION OVER} ACCESSORY PATHWAY (Table 3)

Ventricular pacing was always performed at the apex of the right ventricle. The retrograde effective refractory period of the accessory pathway could be determined before and after the drug in 11 out of the 14 patients (the two patients with a concealed bypass are included). One patient had atrial fibrillation. In two patients the His-AV nodal pathway had a shorter refractory period than the accessory pathway.

In two patients complete block in retrograde conduction over the accessory pathway developed after the drug. The remaining nine patients showed only a minor increase in the effective refractory period of the accessory pathway. 


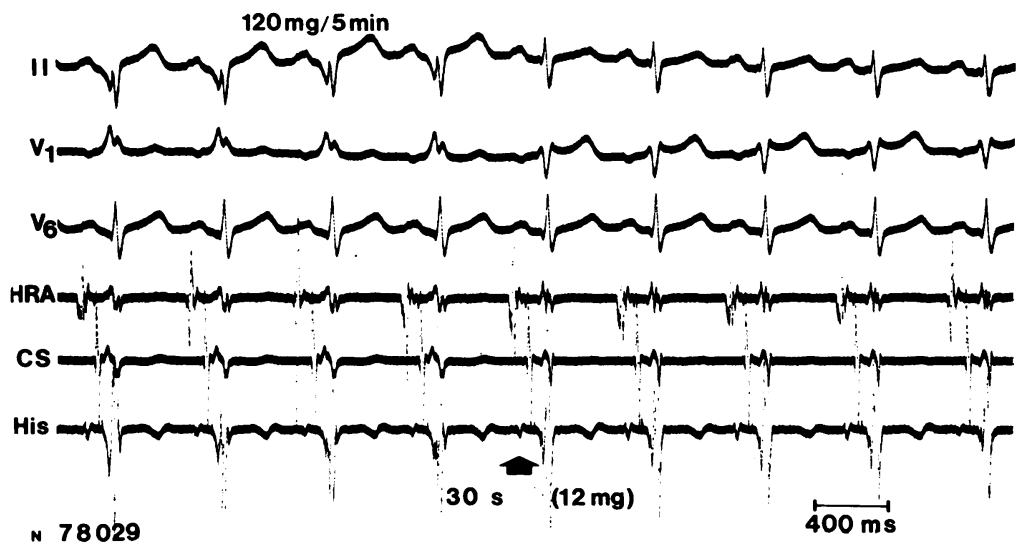

Fig. 3 Development of anterograde block in the accessory pathway during lorcainide injection in a patient with the Wolff-Parkinson-White syndrome. The patient received a total amount of $120 \mathrm{mg}$ over a five minute period. Already after 30 seconds, when $12 \mathrm{mg}$ was given, block occurred in the accessory pathway. Leads II, V1, V6, a high right atrial (HRA) lead, coronary sinus (CS) lead, and a His bundle lead were recorded simultaneously.

\section{EFFECT ON CIRCUS MOVEMENT}

\section{TACHYCARDIAS USING ACCESSORY}

\section{PATHWAY}

Atrial stimulation before and/or after drug administration was done in 13 patients (Table 2). In 10 of these patients we were able to initiate tachycardia before, and in eight patients after, drug administration. In these patients we carefully determined the width of the tachycardia zone. No significant change was seen after drug administration.

Ventricular stimulation before and/or after lorcainide was done in 13 patients (Table 3). In out of these 13 patients we were able to initiate tachycardia before, and in four patients after, lorcainide. No significant change in the width of the tachycardia zone occurred after drug administration.

EFFECT OF LORCAINIDE ON HEART RATE DURING TACHYCARDIA AND TERMINATION OF TACHYCARDIA

Before lorcainide all patients showing circus movement tachycardias required at least one extra

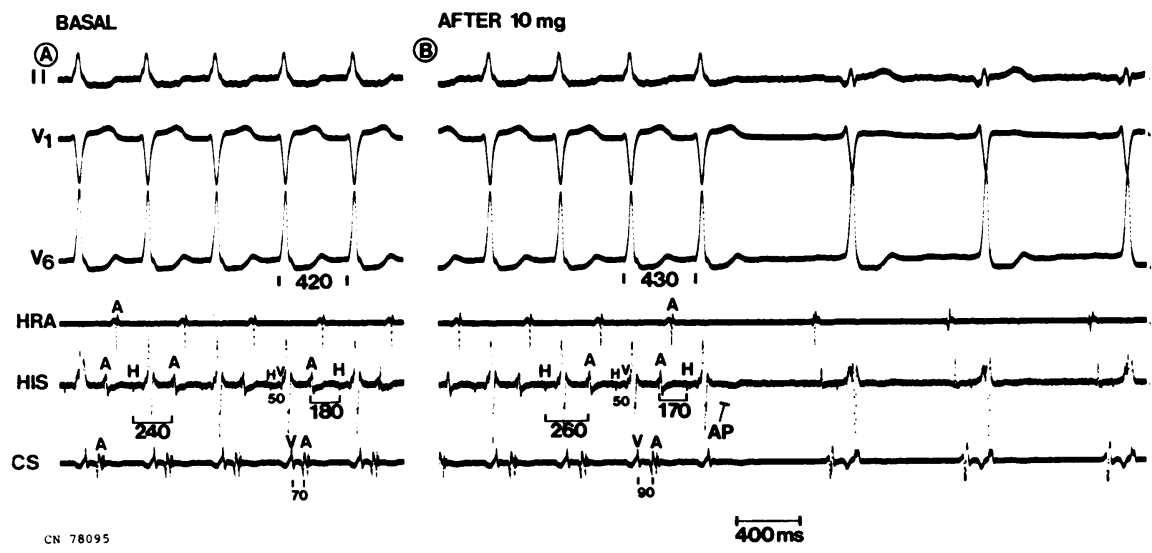

Fig. 4 Termination of circus movement tachycardia during lorcainide injection. On the left (panel A) before drug administration. On the right (panel B) a small amount of lorcainide (10 $\mathrm{mg}$ ) resulted in termination of tachycardia by creating retrograde block in the accessory pathway. Leads II, V1, V6, a high right atrial (HRA) lead, a His bundle lead, and a coronary sinus (CS) lead were recorded simultaneously. 
stimulus from the atrium or ventricle to terminate the arrhythmia.

When lorcainide was given during circus movement tachycardias spontaneous termination of tachycardia by block in the accessory pathway in the VA direction occurred in four out of nine patients (Fig. 4). As shown in Table 4, lorcainide resulted in a significrnt slowing in rate of tachycardia, which was based upon an increase in the HV and VA interval.

Maximal effect on all electrophysiological indices was seen five minutes after the injection of the drug was stopped. The effect of lorcainide lasted for 45 to 60 minutes. No intra-arterial blood pressures were measured. Based upon the frequency of the sinus node and absence of complaints of the patients, we conclude that lorcainide does not have an important effect on blood pressure in the supine position.

No complications resulted from the catheterisation or the drug.

\section{Discussion}

Our data show that lorcainide has no significant effect on the electrophysiological properties of the atrioventricular node or the refractory period of the atrium or ventricle. A decrease was seen in conduction velocity in the His bundle, bundle-branches, and ventricular muscle. The width of the His bundle electrogram, the duration of the HV interval, and the width of the QRS complex during atrial and ventricular stimulation increased significantly.

This effect, as shown in our two patients with subnodal conduction disturbances, makes the drug

Table 3 Effect of lorcainide on retrograde ERP $\mathrm{AP}$ and tachycardia zone in 13 patients with WPW syndrome and concealed accessory pathway

\begin{tabular}{|c|c|c|c|c|c|}
\hline \multirow[b]{2}{*}{$\begin{array}{l}\text { Case } \\
\text { no. }\end{array}$} & \multirow[b]{2}{*}{$\begin{array}{l}\text { Basic cycle } \\
\text { length (ms) }\end{array}$} & \multicolumn{2}{|c|}{ Retrograde ERPAP } & \multicolumn{2}{|c|}{ Tachycardia zone } \\
\hline & & $\begin{array}{l}\text { Before } \\
(m s)\end{array}$ & $\begin{array}{l}\text { After } \\
(m s)\end{array}$ & $\begin{array}{l}\text { Before } \\
\text { (ms) }\end{array}$ & $\begin{array}{l}\text { After } \\
\text { (ms) }\end{array}$ \\
\hline 1 & 500 & 280 & 300 & 0 & 0 \\
\hline 2 & 500 & $<240$ & $<240$ & 0 & 0 \\
\hline 3 & 600 & 330 & 350 & 10 & 0 \\
\hline 4 & 600 & 310 & $>600$ & 5 & 0 \\
\hline 5 & 500 & $<260$ & $<250$ & 60 & 80 \\
\hline 6 & 500 & 280 & 360 & 0 & 0 \\
\hline 7 & 500 & $<220$ & $<240$ & 0 & 10 \\
\hline 8 & 500 & 260 & 290 & 30 & 20 \\
\hline 9 & 500 & $<240$ & $>470$ & 0 & 0 \\
\hline 10 & 420 & $<210$ & $<210$ & 5 & 30 \\
\hline 11 & 475 & $<270$ & NM & 0 & $\mathbf{N M}$ \\
\hline $12 \star$ & 500 & $<210$ & NM & 70 & $\mathrm{NM}$ \\
\hline $13 \star$ & 430 & 220 & 230 & 0 & 0 \\
\hline
\end{tabular}

ERP, effective refractory period; AP, accessory pathway; NM, not measured.

*Patients with a concealed accessory pathway.
Table 4 Effect of lorcainide on $R R, A H, H V$, and $V A$ interval during circus movement tachycardia in nine patients with WPW syndrome or concealed accessory pathway

\begin{tabular}{lrrlllll}
\hline & \multicolumn{2}{l}{ Before $(\mathrm{ms})$} & & \multicolumn{3}{l}{ After $(\mathrm{ms})$} \\
\cline { 2 - 3 } \cline { 6 - 7 } Interval & Range & Mean $\pm S D$ & & Range & Mean $\pm S D$ & $P$ \\
\hline RR & $235-390$ & $289 \pm 48$ & & $260-400$ & $333 \pm 48$ & $<0.01$ \\
AH & $70-180$ & $118 \pm 36$ & & $65-170$ & $110 \pm 41$ & NS \\
HV & $25-55$ & $41 \pm 11$ & & $35-60$ & $47 \pm 9$ & $<0.01$ \\
VA & $80-190$ & $131 \pm 32$ & & $85-240$ & $175 \pm 50$ & $<0.01$ \\
\hline
\end{tabular}

dangerous in patients with impaired conduction in the His-Purkinje system. ${ }^{4-6}$

Lorcainide had a beneficial effect in patients with ventricular arrhythmias. Administration of the drug resulted in slowing followed by termination of tachycardia in four out of five patients. In three of these four patients, however, the tachycardia could still be reinitiated by premature ventricular stimuli.

As we have shown previously, ${ }^{7}$ antiarrhythmic drugs such as procainamide may not prevent reinitiation of tachycardia by timed stimuli and may even increase the width of the tachycardia zone in patients with ventricular tachycardia. The slowing of the tachycardia rate and the tendency to termination, however, suggests that lorcainide could be a clinically effective agent in these patients. Clinically this has been observed both after intravenous and chronic oral administration of the drug. ${ }^{8} 9$

The effect of lorcainide in patients with accessory atrioventricular connection who suffer from circus movement tachycardia or atrial fibrillation is interesting. In most patients there was complete block or distinct prolongation of the refractory period of the accessory pathway in the anterograde direction. In contrast to our previous observations with procainamide, amiodarone, quinidine, and ajmaline, ${ }^{10}$ lorcainide blocked or considerably lengthened the effective refractory period of the accessory pathway in patients with an effective refractory period of their accessory pathway of $270 \mathrm{~ms}$ or less. This has also been observed by others. ${ }^{5}$ This suggests that the drug might be useful in protecting patients with a short refractory period of their accessory pathway, who are at risk for ventricular fibrillation if atrial fibrillation supervenes. As observed with other drugs in patients with the Wolff-Parkinson-White syndrome, the effect of lorcainide on retrograde conduction over the accessory pathway was less obvious. ${ }^{11-13}$

Nevertheless in two out of 10 patients there was complete retrograde block over the accessory pathway. In five patients there was slight pro- 
longation of the effective refractory period of the accessory pathway in retrograde direction. The occurrence of spontaneous termination of circus movement tachycardia in four patients caused by retrograde block of the accessory pathway is important. Lorcainide also slowed the rate of tachycardia by increasing the HV and VA interval.

As reported after amiodarone administration, ${ }^{13}$ reinitiation of circus movement tachycardia by timed atrial or ventricular stimuli was still possible in most patients after lorcainide.

In view of our observations we conclude that the effect of chronic oral lorcainide administration should be assessed in patients with the WolffParkinson-White syndrome and patients with ventricular tachycardia. The drug seems to be contraindicated in patients with sub-atrioventricular nodal conduction disturbances.

\section{References}

1 Carmeliet E, Janssen P, Marsboom R, Van Nueten J, Xhonneux R. Antiarrhythmic, electrophysiologic and hemodynamic effects of lorcainide. Arch Int Pharmacodyn Ther 1978; 231 : 104-30.

2 Wellens HJJ. Value and limitations of programmed electrical stimulation of the heart in the study and treatment of tachycardias. Circulation 1978; 57: 845-53.

3 Wellens HJ, Durrer D. Patterns of ventriculo-atrial conduction in the Wolff-Parkinson-White syndrome. Circulation 1974; 49: 22-31.

4 Manz M, Steinbeck G, Lüderitz B. Action of lorcainide (RT 15889) on sino-atrial node function and intracardial excitation conduction. Herz Kreislauf 1979 ; 11 : 192-7.

5 Kasper W, Meinertz T, Kersting F, Löllgen $H$, Lang $\mathrm{K}$, Just $\mathrm{H}$. Electrophysiological actions of lorcainide in patients with cardiac disease. $\mathcal{f}$ Cardiovasc Pharmacol 1979; 1: 343-52.

$6 \mathrm{Ng} \mathrm{C}$, Gstöttner M, Gmeiner R. Intracardiac electrophysiological effects of lorcainide in man. Eur f Clin Pharmacol 1979; 15: 241-7.

7 Wellens HJJ, Bär FWHM, Lie KI, Düren DR, Dohmen HJ. Effect of procainamide, propranolol, and verapamil on mechanism of recurrent ventricular tachycardia. Am f Cardiol 1977; 40: 579-85.

8 Cocco G, Strozzi C. Initial clinical experience of lorcainide (Ro 13-1042), a new antiarrhythmic agent. Eur f Clin Pharmacol 1978; 14: 105-9.

9 Kesteloot $\mathrm{H}$, Stroobandt R. Clinical experience with lorcainide (R 15 889), a new anti-arrhythmic drug. Arch Int Pharmacodyn Ther 1977; 230: 225-34.

10 Wellens HJ, Bär FW, Gorgels AP. Effect of drugs in WPW syndrome. Importance of initial length of effective refractory period of accessory pathway (abstract). Am f Cardiol 1978; 41: 372.

11 Wellens HJJ, Durrer D. Effect of procaine amide, quinidine, and ajmaline in the Wolff-ParkinsonWhite syndrome. Circulation 1974; 50: 114-20.

12 Wellens HJ. Effect of drugs in the Wolff-ParkinsonWhite syndrome. Adv Cardiol 1975; 14: 233-40.

13 Wellens HJJ, Lie KI, Bär FW, et al. Effect of amiodarone in the Wolff-Parkinson-White syndrome. Am f Cardiol 1976; 38: 189-94.

Requests for reprints to Dr Frits W Bär, Department of Cardiology, University of Limburg, Annadal Hospital, 6201 Bx Maastricht, The Netherlands. 